\title{
Analysis on the Effectiveness of PE FCT Model Based on Cooperative Learning Model
}

\author{
Wei Liu \\ College of Physical Education, Hunan International Economics University, Hunan, Changsha 413000, China \\ Correspondence should be addressed to Wei Liu; hhguosheng001@163.com
}

Received 21 December 2021; Revised 6 January 2022; Accepted 7 January 2022; Published 3 February 2022

Academic Editor: Xin Ning

Copyright $\odot 2022$ Wei Liu. This is an open access article distributed under the Creative Commons Attribution License, which permits unrestricted use, distribution, and reproduction in any medium, provided the original work is properly cited.

\begin{abstract}
Many unique ideas of physical education in colleges and universities were proposed in the 1990s by some experts and scholars in China's sports field, such as "skills education ideas," "happy sports ideas," "lifelong sports ideas," and "health first ideas," and many other higher vocational colleges have begun to implement the inverted classroom teaching model into the teaching practice in physical education classes. Cooperative learning is a method of learning that is systematic and structured. Different approaches, such as collaborative learning, personalized learning, digital learning, and so on, aim to cultivate students" "collaborative learning" and "self-improvement" objectively. The effectiveness of the sports flip classroom teaching mode, which is based on cooperative learning, is examined in this paper. The cooperative learning mode completes the teaching activities in the form of groups in the teaching organization. The cooperative learning mode can help students not only improve their abilities, but also cultivate a sense of cooperation and teamwork in the classroom. We should pay attention to students' participation and cooperative behavior when implementing "cooperative learning" teaching, so that each student has the opportunity to express himself in practice.
\end{abstract}

\section{Introduction}

Applying the FCT mode to physical education can not only improve its effectiveness, but also help to solve the teaching dilemma and promote student development [1]. As a result, we must investigate the efficacy of physical education in the FCT mode in order to better serve the achievement of teaching objectives. In China, the guiding ideology of physical education is gradually aligning with the reform and opening-up requirements. Many distinct college sports teaching ideas, such as "skill education thought," "Happy Sports Thought," "lifelong sports thought," and "health first thought," were proposed by some experts and scholars in China's sports circles in the 1990s. Many higher vocational colleges have begun to introduce the FCT mode into the teaching practice of Physical Education [2]. The failure is attributed to the lack of effort and the lack of help from classmates, which shows a positive way of attribution. China's physical education has formed two relatively centralized teaching guiding ideology, namely "health first" N3 and "lifelong physical education" [3,4]. The former is led and proposed by government departments, while the latter is the guiding ideology of physical education teaching generally recognized by the sports industry. This shows that the guiding ideology of physical education in China is becoming more and more perfect, and has been approved by many physical education teachers and other relevant workers in Colleges and universities [5]. Objectively speaking, the FCT mode focuses on the cultivation of students' abilities such as "collaborative learning", "self-improvement" and so on. The rational application of this teaching mode can comprehensively improve the teaching level of physical education in Higher Vocational Colleges [6]. This phenomenon was caused to some extent by the form of teaching reform at that time [7].

Cooperative learning mode is a systematic and structured learning strategy. According to students' characteristics and abilities, students are divided into cooperative groups to encourage students to trust each other and help each other, so as to improve learning efficiency. In the long history of educational development in China, cooperative learning thinking is actually a very early educational 
concept. More than 2000 years ago, Chinese educator Confucius mentioned and recorded cooperative learning. In the Analects of Confucius, there is a record related to the idea of learning from each other in order to make progress. In another book, Xue Ji, compiled by Confucius, there are words: "If you study alone without friends, you will be ignorant" and "learn from each other and be good at it" $[8,9]$. Physical education classroom teaching meets the environmental conditions of cooperative learning. In physical education classroom, there is no significant difference in physical quality, sports ability and intelligence [10].

In terms of teaching organization, the cooperative learning mode completes teaching activities in the form of groups. The cooperative learning mode can not only improve individual ability in teaching, but also cultivate cooperation consciousness and establish team spirit $[11,12]$. From the teaching process, the cooperative learning model can also fully reflect the important spirit of students as the main body. The biggest difference between cooperative learning teaching and traditional skill teaching is that they have different teaching purposes. It regards students' mastering movement technology and developing skills as the basic teaching objectives, and the ultimate teaching purpose is to develop students' own ability. The implementation of "cooperative learning" teaching pays attention to students' participation and cooperative behavior, so that every student has the opportunity to express himself in practice [13]. In order to meet the needs of market development, cooperation has become a common topic in various fields all over the world. The introduction of cooperative learning mode into sports FCT mode is also to better complete the teaching objectives and achieve the best teaching effect $[14,15]$.

\section{Related Work}

According to literature [16], as early as the early 19th century, General Sylvanus Thayer of West Point Military Academy, which is known for its military civilization, taught courses by letting students learn the course materials they sent in advance before class, and using the valuable time in class for question-answering and group interaction. This type of teaching concept and class mode was already used in flipping classrooms. [17] Literature Most scholars believe that flipping the classroom is to use the media function of information technology, relying on the content of teaching materials, students use the time before class to watch the teaching videos and teaching cards recorded by teachers for autonomous learning and practice, and feed back the problems encountered in learning and practice to the teachers through class exchange groups and going to the office to talk to the teachers. Teachers help students complete exercises and try to solve common problems by guiding them to think independently in class, encouraging them to cooperate and explore, and so on. [18] Literature According to research, flipping the classroom teaching mode is to preview and study some things in the classroom outside of the classroom, particularly the application of multimedia technology, which is just beginning to emerge, provides new learning opportunities for students. According to literature [19], a flipping classroom is a type of teaching structure in which students complete video learning tasks prepared by teachers at home or at another time after class. During class, face-to-face communication is conducted between teachers and students to complete teaching tasks, and homework is reviewed and consolidated after going home at night. Literature [20] through the big data analysis method, the advantage of flipped classroom is to encourage educators to give students more freedom to learn, let everyone choose the most appropriate way to learn and accept new knowledge, and change the traditional way of learning in the classroom. Literature [21] flipped classroom has also received good attention and practice in China. Scholars believe that learning should not only focus on teachers blindly explaining knowledge, but should pay attention to the process of students actively exploring knowledge. Literature [22] proposed that "flipped classroom", also known as inverted classroom, is divided into three parts: before class, in class and after class. Before class, students mainly study the teaching video with micro video as the core released by teachers, and feed back their learning problems online. In class, teachers actively organize reasonable teaching activities, design corresponding teaching modes, focus on solving students' problems, and test and consolidate knowledge after class. Literature [23] through the big data analysis method, the FCT mode can effectively stimulate students' learning interest and enthusiasm, so as to improve the teaching quality. Literature [24] research shows that flipped classroom has many advantages. In classroom teaching, teachers can deepen knowledge, make heterogeneous groups according to different levels of students, implement layered teaching, change the way of focusing on students' practice in the traditional teaching mode, and the atmosphere of the whole classroom is more harmonious. The whole teaching process is a process of mutual assistance, discussion, communication The flexible creative process of feedback and answering doubts is conducive to improve students' autonomous learning and cooperative exploration ability, and continuously improve students' ability to find and solve problems and innovative thinking. Literature [25] proposes that the flipping of classroom form alone can not be called flipped classroom. Flipped classroom mainly through the flipping of teaching process, decomposes the difficulty of knowledge internalization, increases the number of knowledge internalization, and promotes learners' knowledge acquisition, which is its essence.

In this paper, the effectiveness of the physical education flip classroom teaching mode based on cooperative learning mode is analyzed, and it is concluded that there are many factors that affect the effectiveness of teaching, such as teaching mode, teaching environment, teaching content, teachers and students, etc., all of which will have a certain impact on the teaching objectives of physical education flip classroom. Only when teachers have rich cultural knowledge and high professional quality, and students have a solid learning foundation and strong interest in learning, can the teaching effect of PE flip class be improved. 


\section{Construction of FCT Model in Physical Education}

3.1. The Theory of Introducing Cooperative Learning Model into Physical Education Teaching. Cooperative teaching views "Don't Ask For Help People Succeed, but Strive for Everyone's Progress" as a realm pursued by teaching, as well as the ultimate goal and standard of teaching evaluation, transforming norm reference evaluation into standard reference evaluation. To be fair, many factors, such as the teaching environment, teaching mode, teaching content, and so on, can influence the effectiveness of teaching. These factors will theoretically have a significant impact on current teaching objectives in varying degrees and meanings. For example, in basketball instruction, the passer should pass to the position as much as possible, and the receiver should run in place as much as possible when passing and receiving a ball. Only when both sides work together closely will the ball's passing and receiving effect be optimal. When a ball is not passed and received well, however, the passer always blames the receiver for not receiving well, and the receiver always blames the passer for not passing well, resulting in contradictions between the two sides. Physical education teachers should take this opportunity to guide seriously, explain the importance of cooperation to both sides, and emphasize that the learning effect will only be positive if both sides work hard to cooperate. The mode of instruction and the content of instruction have a big impact on how effective a teacher is. The whole senior year is taught by myself, using unified teaching materials and unified progress, providing students with the same learning materials, and teaching is carried out in the same external environment. This type of teaching can be divided into three links before class, during class, and after class, according to the guidance of the FCT mode theory, and the three links do not exist independently. Therefore, on the basis of previous studies, the specific process of the implementation of flipped classroom back jump teaching mode is designed, as shown in Figure 1.

The coherence quality of the text is defined as the joint probability distribution of $T\left(S_{1}, S_{2}, \ldots, S_{n}\right)$, which contains $M$ entity words, $e_{1} \ldots e_{m}$, which shows the distribution of entity words in each sentence of the text.

$$
P_{\text {coherence }}(T)=p\left(e_{1} \ldots e_{m}, S_{1} \ldots S_{n}\right) .
$$

We further assume that each entity word is selected into the text relatively independently of other entity words.

$$
P_{\text {coherence }}(T)=\prod_{j=1}^{m} p\left(e_{j}, S_{1} \ldots S_{n}\right) .
$$

Will $P\left(e_{j} ; S_{1} \ldots s_{n}\right)$ is defined as the probability distribution of the transition sequence of entity word $e_{j}$ in $n$ sentences. $P\left(e_{j} ; S_{1} \ldots s_{n}\right)$ are estimated from the columns of the grid.

$$
P_{\text {coherence }}(T)=\prod_{j=1}^{m} p\left(r_{i, j} \mid r_{(i-h), j} \ldots r_{(i-1), j}\right) .
$$

$R_{i j}$ represents the grammatical role of entity word EJ in the ith sentence. $P\left(\mathrm{RI}, j \mid r_{1}, J \ldots R(i-1), J\right)$ is estimated by the standard cooperative learning independence hypothesis. Suppose we use first-order cooperative learning. For the entity word "Pinochet", $P$ (Pinochet; $S_{1} \ldots S_{6}$ ) can be obtained by multiplying $P(o), P(s \mid o), P(-\mid s), P(o \mid-), P(s \mid o)$ and $P(-\mid$ s).

Finally, the probability value of each column is normalized by the length of the column, while the probability value of the whole text is normalized by the number of columns

$$
P_{\text {coherence }}(T) \approx \frac{1}{m \times n} \sum_{j=1}^{m} \sum_{i=1}^{n} p\left(r_{i, j} \mid r_{(i-h), j} \ldots r_{(i-1), j}\right) \text {. }
$$

For any text $d_{j} \in D$, we use a $T$-dimensional vector to represent it.

$$
\bar{d}_{j}=\left(w_{1 j}, w_{2 j}, \ldots, w_{t j}\right)
$$

In this formula, the vector component $w_{t j}$ represents the weight value corresponding to the I-th word $k_{i}$ of the document $d_{j}$, and $t$ is the total number of words in the text. In Boolean model, the value of $w_{t j}$ is 0 or 1 ; Among them, because VSM uses the strategy of "partial matching", the value range of $w_{t j}$ is between [0,1]. This weight setting method is very important for the generation and subsequent processing of text vectors. The TF-IDF function is commonly used in existing methods, and the weight of each word mainly depends on the statistical information of its frequency in different environments.

$$
\mathrm{TF}-\mathrm{IDF}_{i j}=\frac{n_{i, j}}{\sum_{k} n_{k, j}} \times \log \frac{|D|}{\left|\left\{j: t_{i} \in d_{j}\right\}\right|} .
$$

In the above formula, $N i$ and $j$ are the frequency of a word used in a text, and the denominator represents the sum of the frequencies of all words used in a text $D \mid$ represents the total number of compositions in the corpus $\mid\left\{J: T_{i} \in \mathrm{DJ}\right\}$ indicates the number of compositions containing words (i.e. $N i, J \neq 0)$. Because when a word is not collected by the corpus, the divisor will be zero, so in order to deal with this kind of phenomenon, $1+\mid\{J: T i \in \mathrm{D} J\}$ is generally used $\mid$.

For two-dimensional space, the similarity between vectors is calculated according to the vector dot product formula

$$
\cos (\theta)=\frac{\sum_{i=1}^{n}\left(X_{i} \times Y_{i}\right)}{\sqrt{\sum_{i=1}^{n}\left(X_{i}\right)^{2} \times \sqrt{\sum_{i=1}^{n}\left(Y_{i}\right)^{2}}}}
$$

The formula for calculating the attention degree of the $J$ th service value feature in the I-th service provider is as follows

$$
\mathrm{BF}_{(i, j)}=\sum_{B \_C}^{q} \sum_{\text {Feature }}^{m} \sum_{b}^{j} \text { Value. }
$$

Text with higher probability of $P_{\text {coherence }}(T)$ is more coherent than text with lower probability. 


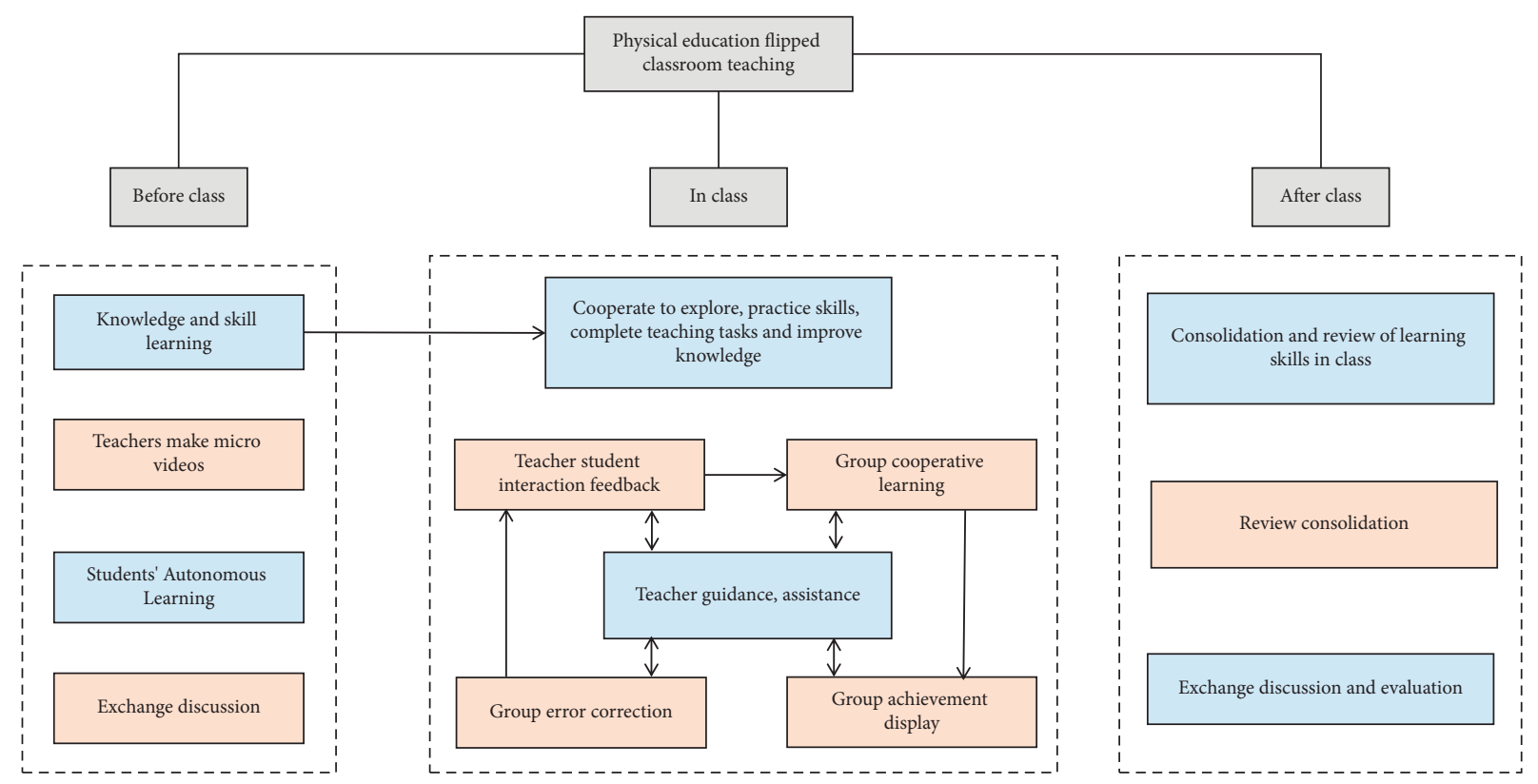

FIGURE 1: Flip the flow chart of organization and implementation in classroom teaching.

Cooperation is a theme that can be found throughout the study of physical education. From time to time, cooperative factors can be found in collective cooperative projects. Individual projects also require peer support and encouragement. The key is whether teachers can grasp the opportunity of cooperative education and recognize the value of cooperative learning in order to use physical education teaching content in their classrooms. Design and arrange cooperative learning elements so that students understand the importance of cooperative learning and receive cooperative learning education in an imperceptible manner through physical education learning. This is because the cooperative learning model teaches them that if they work hard and work together with their classmates, they can succeed, demonstrating a strong sense of confidence and self-efficacy. The winners attribute their failure to their poor ability and high difficulty of the task, which leads to the negative side, reducing their sense of self-efficacy. The successful students in the control and simulation classes attribute their success to their own ability and the difficulty of the task too much, which easily makes them self-confident and tends to be conceited; the losers attribute their failure to their poor ability and high difficulty of the task, which leads to the negative side, thus reducing their sense of self-efficacy.

3.2. Construction of Sports Cooperative Learning Mode. In the word pattern, modern Chinese dictionary explains that it is "the standard form of something or the standard style that people can follow". In English, it is the same word as "model" and "model", both of which are "model". Western academic circles interpret model as a knowledge system between experience and theory. Cooperative learning mode is an activity with relatively fixed operating procedures and strategies based on the overall performance of the group to promote students' learning in skills, morality and social development. Group division is the foundation, and the focus of implementation is to make use of the interaction between dynamic factors in the teaching process. Cognition mode and method mode should be the two basic meanings of teaching mode. Based on the above viewpoints, we define the teaching model as "a typical teaching method system with stable structure and function formed in teaching practice under the guidance of certain teaching theories and teaching ideas." Thus, the teaching mode is the unity of teaching forms and methods. From this, it concludes that the connotation of cooperative learning model includes organizational form, driving force, mutual aid relationship and evaluation basis. Explain separately, such as organizational form. The teaching mode of dividing groups is not necessarily cooperative learning mode, but cooperative learning mode must be group teaching. Scientific organization and activities of cooperative groups are the core link of cooperative learning teaching, which is also its fundamental feature. Cooperative learning mode will be based on cooperative groups, so we should pay attention to the cultivation of cooperative groups in the teaching process. Based on the comprehensive understanding of the concepts of cooperative learning and teaching mode, and the characteristics of middle school physical education, the cooperative learning teaching mode is defined as a relatively stable and orderly structure with group cooperative learning as the basic form under the cooperative learning theory. The "peer relationship" in the teaching process has gradually expanded from "studentstudent" to "student-teacher" with the continuous penetration of the cooperative learning model. At the same time, more emphasis is placed on the interaction between dynamic factors of teaching, including even mutual assistance within 
schools and among society. Therefore, teaching creates the zone of proximal development not only in teachers' teaching, but also in the cooperation of strong peers.

\section{Experimental Research on Cooperative Learning Model in Middle School Physical Education}

4.1. Experimental Design. Count the height, weight and gender of students, test the relevant physical indexes and basic technical level of students, and group them according to the principle of "heterogeneity within groups and homogeneity between groups"; The communication among team members is designed as on-site communication, establishing chat group, telephone contact, etc. According to the needs and actual situation, so as to ensure the high efficiency of communication among team members; Each team shall formulate brief and practical rules and regulations to ensure learning and practice inside and outside the classroom. Teach according to the teaching process, as shown in Figure 2.

(i) Cooperative learning teaching mode can enhance students' interest in physical education

(ii) Cooperative learning teaching mode can improve students' physical education performance

(iii) Cooperative learning teaching model can enhance students' sense of cooperation and improve the relationship between students

(iv) Cooperative learning teaching model can improve students' self-efficacy

(v) The cooperative learning teaching model can improve the structure of classroom interaction. The sample has passed the pre-test. Among the six classes in grade one of Linyi Normal high school, two classes with no significant difference in comprehensive physical quality are selected. One class is the experimental class (male 40 , female 40 ), using the cooperative learning model, and the other class is the control class (male 40, female 42). The dependent variables of the traditional teaching model are measured

(vi) Students' interest in Physical Education

(vii) Student academic performance

(viii) The frequency of interaction between teachers and students, teachers' class, teachers' group, students, students' group and students' class in physical education class

(ix) Students' attribution of success/failure

(x) There was no significant difference in three basic qualities between boys and boys, girls and girls in the experimental class and the control class

The design of learning evaluation, according to the requirements of the new "Outline" and the comprehensive application of various evaluation methods and methods, should downplay the functions of screening and selection, strengthen the functions of encouragement and development, incorporate the progress of students into the evaluation content. Teachers need to carefully design classroom activities to help complete the internalization of knowledge. According to the students' learning information obtained by teachers on the mobile learning platform before class, we can know the degree of students' mastery of new knowledge. Make a classroom design that meets the students' learning status as shown in Figure 3.

I teach the entire senior year, using unified teaching materials and progress, providing students with the same learning materials, and instructing in the same external environment. Following the training, two senior teachers with many years of experience in the classroom observe and record classroom interactions in two different teaching modes to create an observation record table. It is to choose test indicators and measurement tools that correspond to them. The relevant physical fitness test indexes are derived from the national student physical health standard and the volleyball professional athlete selection test method. The technical level test index is derived from the volleyball technical level test method used in sports measurement. The group cohesion power scale, which is based on Carron et algroup.'s environment questionnaire, is used to test the index of group cohesion.

4.2. Results and Analysis. It is usually arranged after the teacher has finished the teaching content and the group has conducted cooperative study and practice for a period of time. When investigating students' expected teaching forms and the degree of completion of students' tasks, it is mainly from students' understanding of pre-class learning tasks; The students in the experimental class and the control class were investigated and analyzed from four aspects: whether they think that learning before class is helpful, whether they like cooperative learning, and whether they are willing to learn some knowledge about PE flip class teaching after completing the task of PE flip class teaching. The survey results are shown in Figure 4 below.

Each group will have a one-minute fixed-point shooting competition, with the number of goals determining the group's score: dribbling layups will be a relay competition for each person, with the layups not making up for each other, and the group's score will be determined by the number of times spent by the group. Each member of the group will be numbered by the opponent before the competition in the teaching competition. If the first student scores a goal, he will receive one point, and if the second student scores two goals, he will receive two points. Three experiments were carried out in turn. As shown in Figures 5-7.

From its literal meaning, physical education can be regarded as a kind of education and cultivation of the body. If students' body has been developed and their physique has been strengthened, can it be regarded as students' success and give a positive evaluation? There is no doubt that the answer should be yes.

Students with good innate physical qualities will receive a positive and high evaluation regardless of how hard they 


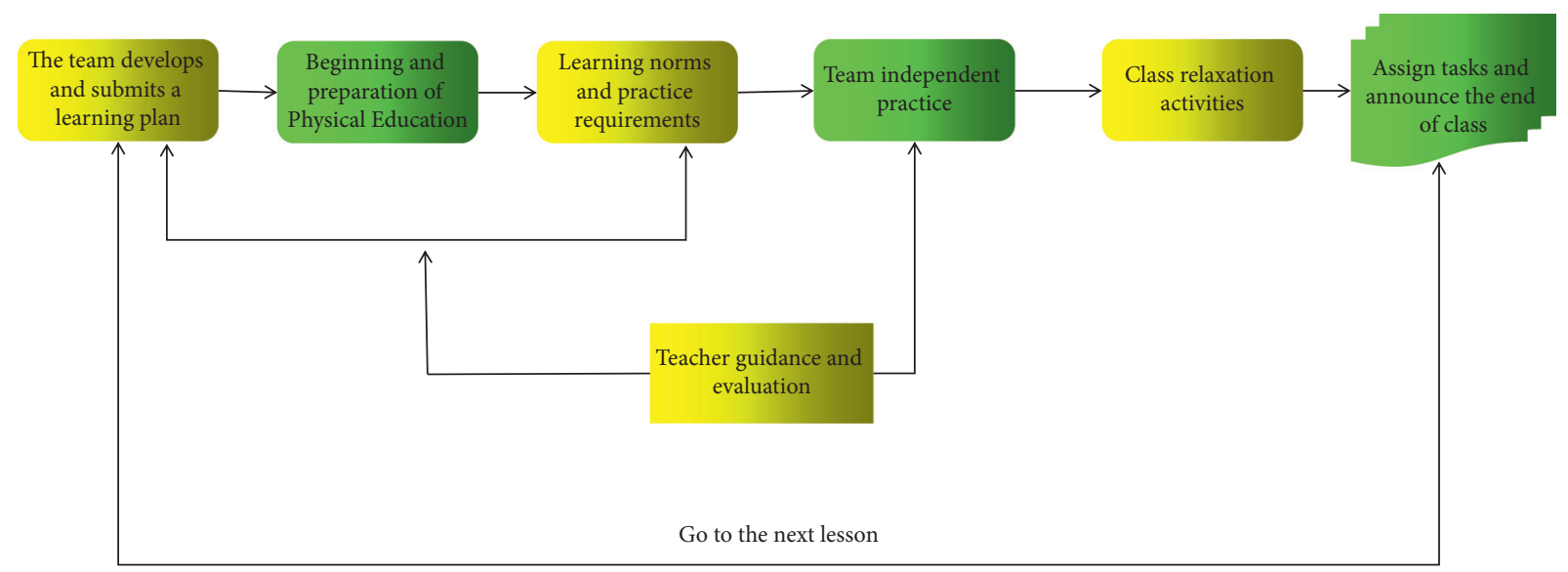

FIgURE 2: Experimental hypothesis of teaching process in team teaching mode.

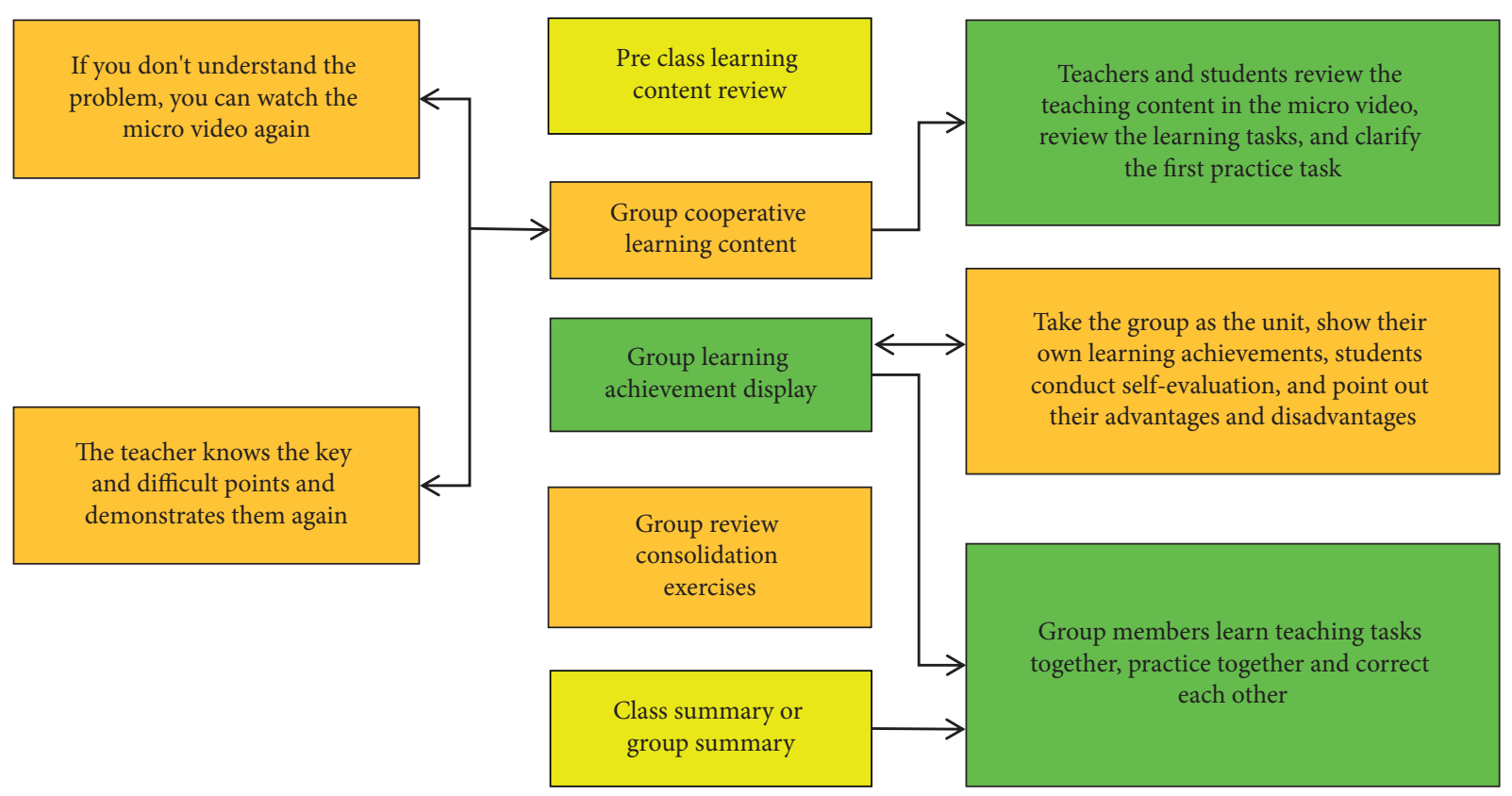

Figure 3: Specific organization diagram in PE FCT mode.

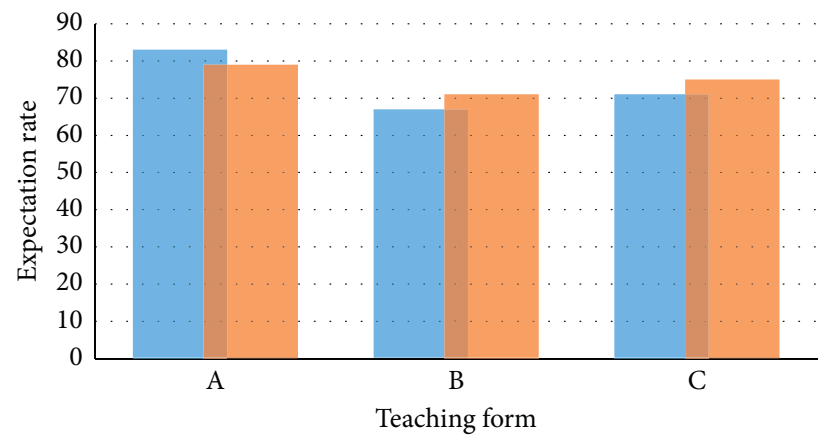

- Flipped classroom teaching mode

- Traditional teaching mode

FIGURE 4: Analysis chart of students' expected learning forms. A : Learning before class can help me learn technical movements more decisively. B Do you think cooperative learning is better than independent learning. C Are you willing to learn more about the classroom teaching of physical education. 


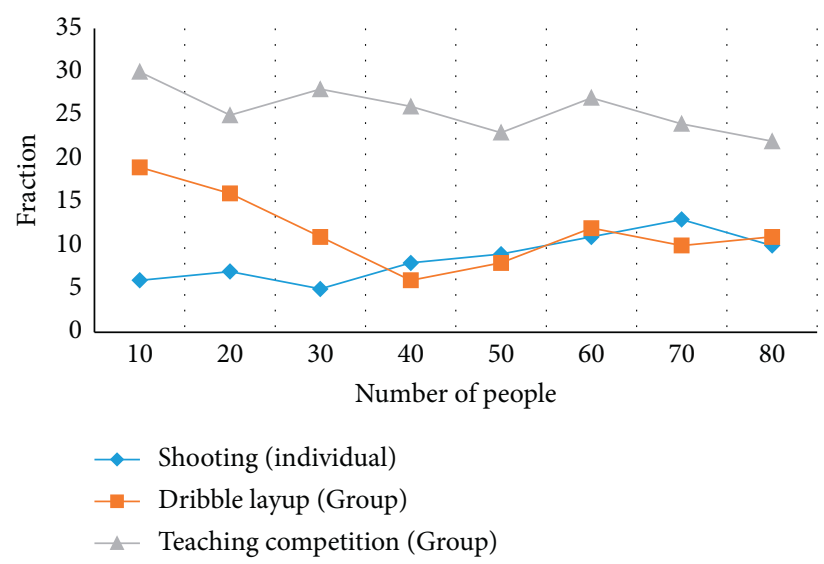

Figure 5: Scoring method of basketball in the first experiment.

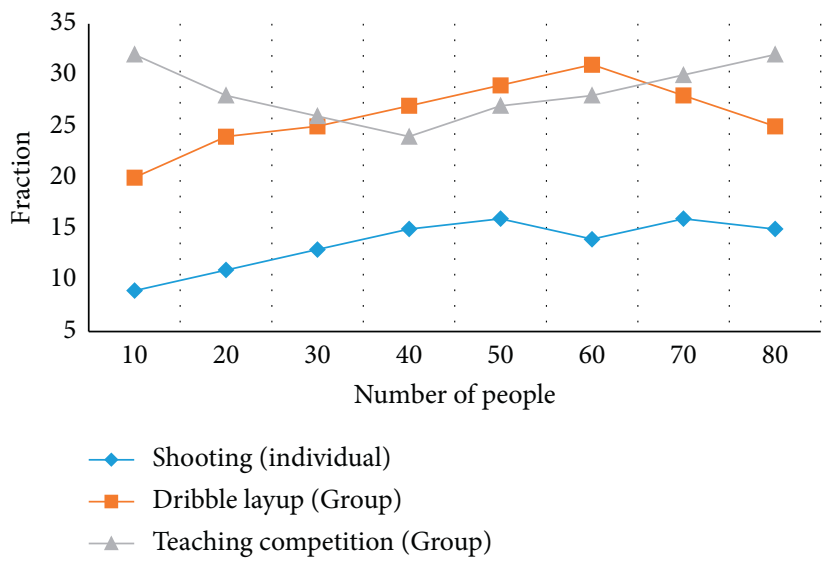

Figure 6: Scoring method of basketball in the second experiment.

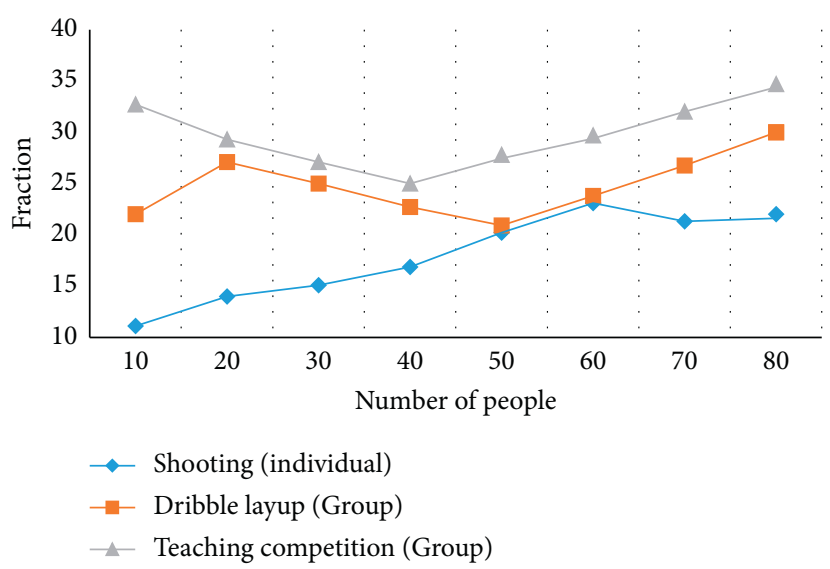

Figure 7: Scoring method of basketball in the third experiment.

work or progress in physical education class. Those students with poor innate physical quality, on the other hand, have made great progress no matter how hard they try, and eventually they will only receive a low or even negative evaluation, and will become losers in learning, dampening their enthusiasm for learning and losing interest in physical education class. Three experiments were conducted, and the subsequent investigation of students' interest in studying in physical education class confirmed this point. As shown in Figures 8-10.

According to the results of the study, students in the experimental class attribute their success primarily to their 


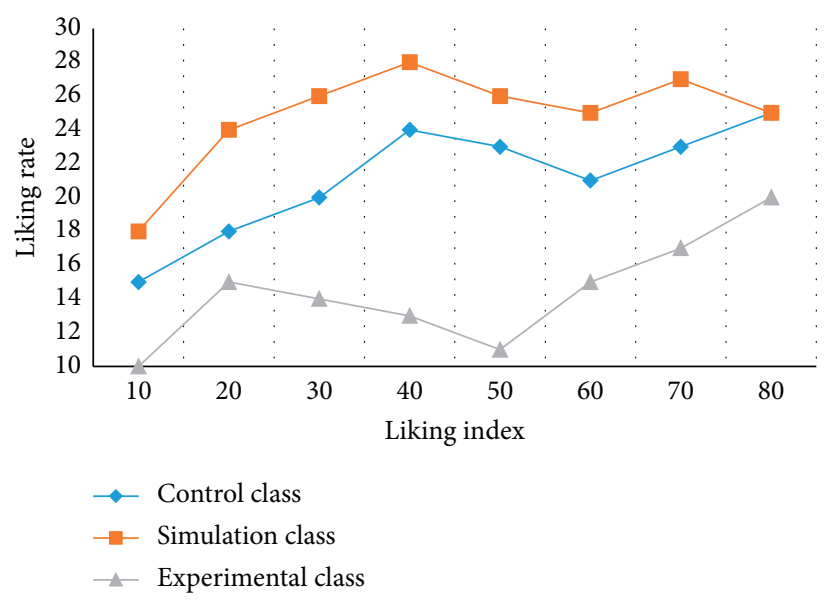

Figure 8: Survey of students' interest in physical education for the first time.

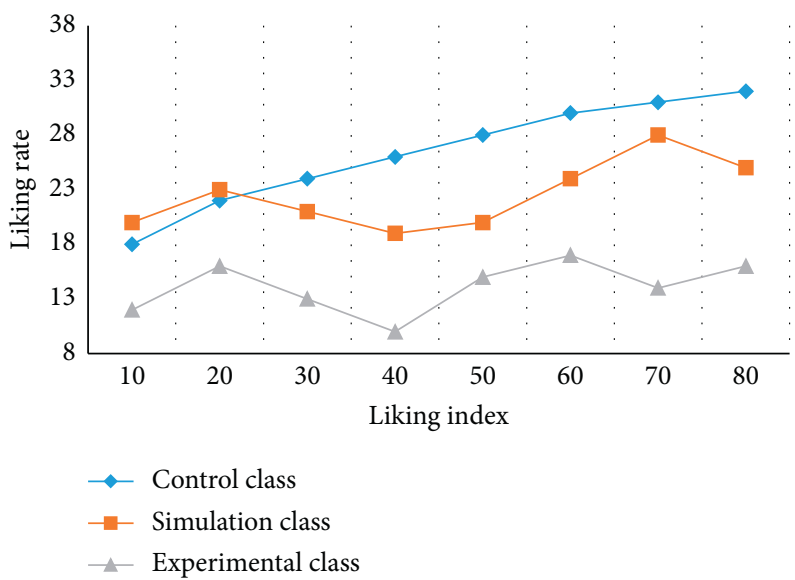

Figure 9: Survey of students' interest in physical education for the second time.

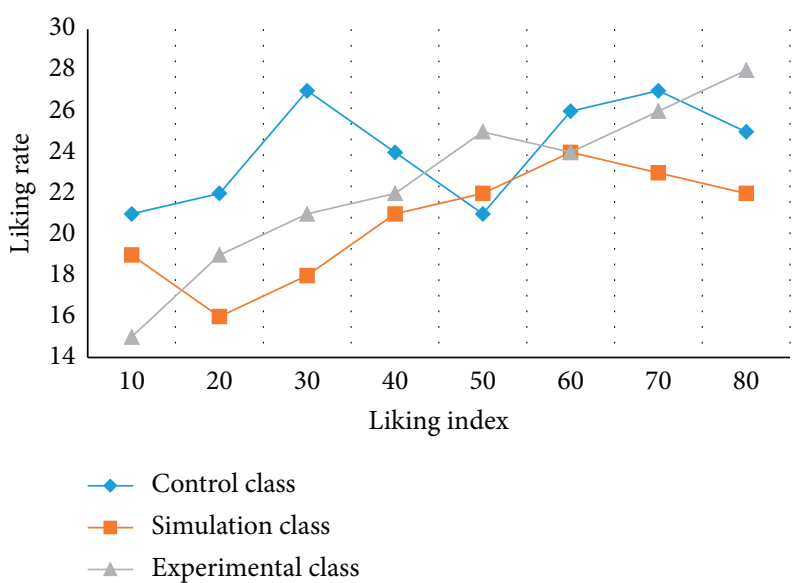

FIGURE 10: Survey of students' interest in physical education for the third time.

hard work, ability, and the assistance and cooperation of their classmates. The failure is attributed to a lack of effort and lack of assistance from classmates, demonstrating a positive attribution style. This is because the cooperative learning model teaches them that if they work hard and work together with their classmates, they can succeed, demonstrating a strong sense of confidence and self-efficacy. The winners attribute their failure to their poor ability and high difficulty of the task, which leads to the negative side, reducing their sense of self-efficacy. The successful students in 
the control and simulation classes attribute their success to their own ability and the difficulty of the task too much, which easily makes them self-confident and tends to be conceited; the losers attribute their failure to their poor ability and high difficulty of the task, which leads to the negative side, thus reducing their sense of self-efficacy. Cooperative teaching views "Don't Ask For Help People Succeed, but Strive for Everyone's Progress" as a realm pursued by teaching, as well as the ultimate goal and standard of teaching evaluation, transforming norm reference evaluation into standard reference evaluation. This will undoubtedly pique students' interest in physical education class and increase their enthusiasm for learning.

\section{Conclusions}

Students' ability to communicate with others is improved when cooperative learning mode is used in physical education flip classroom teaching mode. As a result, it can be concluded that the organizational form, driving force, mutual aid relationship, and evaluation basis all fall under the umbrella of cooperative learning model. Explain each point separately, such as the organizational structure. The teaching mode of dividing groups is not always cooperative learning mode, but it must be cooperative learning mode. The general teaching method only has the effect of assisting students in improving skills related to examination content, whereas cooperative learning is more beneficial in assisting students in mastering all aspects of technical tactics in sports, including examination skills. Students' skills, tactical level, and physical fitness improved in the experimental class using the flipping classroom teaching mode. As a result, teaching creates a zone of rapid development, which is reflected not only in the teaching of teachers, but also in the cooperation of stronger peers.

\section{Data Availability}

The data used to support the findings of this study are included within the article.

\section{Conflicts of Interest}

The author does not have any possible conflicts of interest.

\section{Acknowledgments}

This study was supported without any funding.

\section{References}

[1] N. Fidalgo-Blanco, M. L. Sein-EchaluCe, and F. J. GarcíaPealvo, "Ontological flip teaching: a flip teaching model based on knowledge management," Universal Access in the Information Society, no. 4, pp. 1-15, 2017.

[2] C. Sanchez-Azqueta, E. Cascarosa, and S. Celma, "Application of a flipped classroom for model-based learning in electronics," International Journal of Engineering Education, vol. 35, no. 3, pp. 938-946, 2019.

[3] M. D. Johnson, L. S. Behar-Horenstein, and M. A. Maciver, "Assessing the effectiveness of a cadaveric teaching model for performing arthrocentesis with veterinary students," Journal of Veterinary Medical Education, vol. 43, no. 1, pp. 1-7, 2016.

[4] R. Christopher and Tainter, "The "flipped classroom" model for teaching in the intensive care unit," Journal of Intensive Care Medicine, vol. 32, no. 3, pp. 187-196, 2017.

[5] A. Martina and Ra, "Unpacking "active learning": a combination of flipped classroom and collaboration support is more effective but collaboration support alone is not," Journal of Chemical Education, vol. 94, no. 10, pp. 1406-1414, 2017.

[6] J. Lampe, E. Rüde, Y. Papadopoulos, and S. Kabir, "Modelbased assessment of energy-efficiency, dependability, and cost-effectiveness of waste heat recovery systems onboard ship," Ocean Engineering, vol. 157, no. JUN.1, pp. 234-250, 2018.

[7] D. Friedrich, "Mixing fossil- and bio-polymers for internalisation of environmental damage: an evidence-based modeltheoretical economic analysis," Ecological Economics, p. 186, 2021.

[8] A. P. Coulibaly, P. Pezuk, P. Varghese et al., "Neutrophil enzyme myeloperoxidase modulates neuronal response in a model of subarachnoid hemorrhage by venous injury," Stroke, vol. 52, no. 10, pp. 3374-3384, 2021.

[9] J. Philippe, S. Jonas, and B. Arno, "Effectiveness of a brief teaching scenario in a phantom-based learning model for students to achieve ultrasound-guided vascular access-a prospective study," Indian Journal of Surgery, pp. 1-7, 2020.

[10] B. K. Gorres-Martens, A. R. Segovia, and M. T. Pfefer, "Positive outcomes increase over time with the implementation of a semiflipped teaching model," Advances in Physiology Education, vol. 40, no. 1, pp. 32-37, 2016.

[11] J. Blom, W. den Elzen, A. H. van Houwelingen et al., "Effectiveness and cost-effectiveness of a proactive, goaloriented, integrated care model in general practice for older people. A cluster randomised controlled trial: integrated Systematic Care for older People-the ISCOPE study," Age and Ageing, vol. 45, no. 1, pp. 30-41, 2016.

[12] R. Singh, N. Gupta, and B. Srivastava, "Preferred mode of teaching - for attitude, aptitude and effectiveness of dental students," Journal of the Anatomical Society of India, vol. 65, no. 1, pp. 48-50, 2016.

[13] W. Xiaoling, F. Honghao, and S. Kunling, "Cost-effectiveness analysis of double low-dose budesonide and low-dose budesonide plus montelukast among pediatric patients with persistent asthma receiving Step 3 treatment in China[J]," Journal of Medical Economics, vol. 23, no. 12, pp. 1630-1639, 2021.

[14] G. Shiha, R. Soliman, N. N. H. Mikhail, and P. Easterbrook, "An educate, test and treat model towards elimination of hepatitis $\mathrm{C}$ infection in Egypt: feasibility and effectiveness in 73 villages," Journal of Hepatology, vol. 72, no. 4, pp. 658-669, 2020.

[15] M. Andrea, B. Laura, and F. Elisa, "Medical therapy, radiofrequency ablation or cryoballoon ablation as first-line treatment for paroxysmal atrial fibrillation: interpreting efficacy through restricted mean survival time and network meta-analysis," Reviews in Cardiovascular Medicine, vol. 22, no. 3, pp. 557-561, 2021.

[16] "mproved U-net," International Journal of Applied Mathematics and Computer Science, vol. 30, no. 3, pp. 399-413, 2020.

[17] M. R. Penny, Z. J. Cao, B. Patel et al., "Three-dimensional printing of a scalable molecular model and orbital kit for organic chemistry teaching and learning," Journal of Chemical Education, vol. 94, no. 9, pp. 1265-1271, 2017. 
[18] P. Xu, Y. Chen, W. Nie et al., "The effectiveness of a flipped classroom on the development of Chinese nursing students' skill competence: a systematic review and meta-analysis," Nurse Education Today, vol. 80, pp. 67-77, 2019.

[19] Q. Jian, "Effects of digital flipped classroom teaching method integrated cooperative learning model on learning motivation and outcome," The Electronic Library, vol. 37, no. 5, pp. 842-859, 2019.

[20] C. Kostaris, S. Sergis, and D. G. Sampson, "Investigating the potential of the flipped classroom model in K-12 ICT teaching and learning: an action research study[J]," Educational Technology \& Society, vol. 20, no. 1, pp. 261-273, 2017.

[21] K. Khalaf, M. El-Kishawi, and S. Mustafa, "Effectiveness of technology-enhanced teaching and assessment methods of undergraduate preclinical dental skills: a systematic review of randomized controlled clinical trials[J]," BMC Medical Education, vol. 20, pp. 1-13, 2020.

[22] R. Kay, T. Macdonald, and M. Digiuseppe, "A comparison of lecture-based, active, and flipped classroom teaching approaches in higher education," Journal of Computing in Higher Education, vol. 31, no. 3, pp. 449-471, 2019.

[23] Bouvet, Cyrille, and Battin, "A systematic review of the effectiveness of the clubhouse model," Psychiatric Rehabilitation Journal, vol. 39, no. 4, pp. 305-312, 2016.

[24] J. Scheerens and S. Blömeke, "Integrating teacher education effectiveness research into educational effectiveness models," Educational Research Review, vol. 18, pp. 70-87, 2016.

[25] Y.-b. Liu, L.-1. Xue, H.-p. Xue, and P. Hou, "Effectiveness of education courses in enhancing clinical educators' teaching ability," The Journal of Continuing Education in Nursing, vol. 50, no. 8, pp. 367-373, 2019. 